TẠP CHÍ KHOA HỌC ĐẠI HỌC TÂN TRÀO

ISSN: $2354-1431$

http://tckh.daihoctantrao.edu.vn/

\title{
Trường Đại học Tân Trào với vai trò đào tạo nguồn nhân lực cho sự phát triển kinh tế xã hội của tỉnh Tuyên Quang và một số tỉnh vùng Tây Bắc giai đoạn 2006-2015
}

\author{
Nguyễn Mỹ Nga $a^{a^{*}}$; Pham Thị Thu Huyền ${ }^{b}$; Nguyễn Mỹ Việt $t^{b}$ \\ ${ }^{a}$ Truò̀ng THCS Hưng Thành, tỉnh Tuyên Quang \\ ${ }^{b}$ Trường Đại học Tân Trào \\ *Email:mynga.green@gmail.com
}

\section{Thông tin bài viết}

Ngày nhận bài:

26/01/2018

Ngày duyệt đăng:

$10 / 3 / 2018$

\section{Tù khoá:}

Sinh viên; nguồn nhân lưc; cán bộ; công chức; Tây Bắc.

\section{Tóm tắt}

Trường Đại học Tân Trào được thành lập ngày 14 tháng 8 năm 2013 theo quyết định số $1404 / \mathrm{Q} Đ-T T g$ của Thủ tướng Chính phủ Việt Nam, là một trường đại học công lập có nhiệm vụ đào tạo, nghiên cứu khoa học và hợp tác quốc tế của tỉnh Tuyên Quang và khu vực Tây Bắc. Đến nay, Trường Đại học Tân Trào đã đào tạo cho tỉnh Tuyên Quang và các tỉnh trong cả nước hàng ngàn cán bộ quản lý, giáo viên cho ngành giáo dục và các ngành khác. So sánh số sinh viên của Trường Đại học Tân Trào được đào tạo giai đoạn 2006-2015 với số cán bộ, công chức, cán bộ quản lý của tỉnh Tuyên Quang, đồng thời việc thống kê số sinh viên của các tỉnh lân cận được đào tạo bởi Trường Đại học Tân Trào, đã khẳng định được vị trí và vai trò to lớn trong công tác đào tạo nguồn nhân lực phục vụ sự nghiệp phát triển kinh tế - xã hội của tỉnh Tuyên Quang nói riêng, khu vực Tây Bắc và cả nước nói chung của Đại học Tân Trào.

\section{1. Đặt vấn đề}

Trường Đại học Tân Trào tiền thân là Trường Sơ cấp Sư phạm Tuyên Quang được thành lập từ năm 1959. Đến tháng 02/1999, Thủ tướng Chính phủ ra Quyết định thành lập Trường $\mathrm{Cao}$ đẳng Sư phạm Tuyên Quang. Ngày 30/6/2011, Bộ Giáo dục và Đào tạo ký Quyết định số 2651/QĐ-BGDĐT đổi tên thành trường $\mathrm{Cao}$ đẳng Tuyên Quang để đào tạo đa ngành. Ngày 14/8/2013, Thủ tướng Chính phủ đã ký Quyết định số 1404/QĐ-TTg thành lập Trường Đại học Tân Trào trên cơ sở nâng cấp Trường Cao đẳng Tuyên Quang.

Trường Đại học Tân Trào nằm giữa khu vực miền núi phía Bắc, là một đơn vị sự nghiệp trực thuộc UBND tỉnh Tuyên Quang và chịu sự quản lý nhà nước về chuyên môn của Bộ Giáo dục và Đào tạo, thực hiện nhiệm vụ đào tạo, nghiên cứu khoa học và hợp tác quốc tế với tất cả các ngành, lĩnh vực theo nhu cầu xã hội. Với đặc thù của các chuyên ngành đào tạo và phương thức tuyển sinh, Trường Đại học Tân Trào đã và đang đào tạo sinh viên của trên 30 tỉnh thành trong cả nước, nhưng do vị trí địa lý nên sinh viên của Trường Đại học Tân Trào chủ yếu là ở các tỉnh Tuyên Quang, Hà Giang và một số tỉnh vùng Tây Bắc. Trong nhiều năm qua, Trường Đại học Tân Trào đã đào tạo và cho tốt nghiệp hàng chục nghìn sinh viên đóng góp vào sự phát triển kinh tế xã hội, tạo nguồn nhân lực cho ngành giáo dục và các ngành khác của tỉnh Tuyên Quang cũng như các tỉnh trong khu vực Tây Bắc. So sánh số lượng và kết quả đào tạo của Trường Đại học Tân Trào trong giai đoạn 2006-2015 với số lượng cán bộ, công chức, viên chức các cơ quan đảng, đoàn thể, chính quyền, mặt trận tổ quốc các cấp và số lượng cán bộ, viên chức ngành giáo dục và đào tạo của tỉnh Tuyên Quang, đồng thời thống kê số lượng sinh viên tốt nghiệp về công tác tại một số tỉnh lân cận đã cho thấy vai trò to lớn và sự tác động không nhỏ của nguồn nhân lực do Trường Đại học Tân Trào đào tạo đối với sự phát triển kinh tế-xã hội của khu vực Tây Bắc. 
2. Kết quả đào tạo của Trường Đại học Tân Trào giai đoạn 2006-2015

\subsection{Giai đoan 2006-2012}

Trong giai đoạn 2006-2012, Trường Đại học Tân Trào đào tạo nguồn nhân lực từ trình độ cao đẳng trở xuống. Đối với nguồn nhân lực có trình độ cao đẳng, các ngành thuộc khối tự nhiên, kỹ thuật đào tạo được 825 sinh viên, trong đó hộ khẩu thuộc tỉnh Tuyên Quang là 618 sinh viên và thuộc các tỉnh khác là 207 sinh viên, các chuyên ngành xã hội là 873 sinh viên, trong đó hộ khẩu Tuyên Quang là 647 sinh viên và thuộc các tỉnh khác là 226 sinh viên. Đối với nguồn nhân lực có trình độ trung cấp chuyên nghiệp, nhà trường đã đào tạo được 1018 người, trong đó hộ khẩu thuộc tỉnh Tuyên Quang là 964 người và thuộc các tỉnh khác là 54 người (Số lượng học sinh, sinh viên tốt nghiệp thể hiện trong Biểu đồ 1 , số sinh viên các ngành đào tạo hệ cao đẳng được thể hiện trong Biểu đồ số 2 , hệ trung cấp chuyên nghiệp trong Biểu đồ 3).

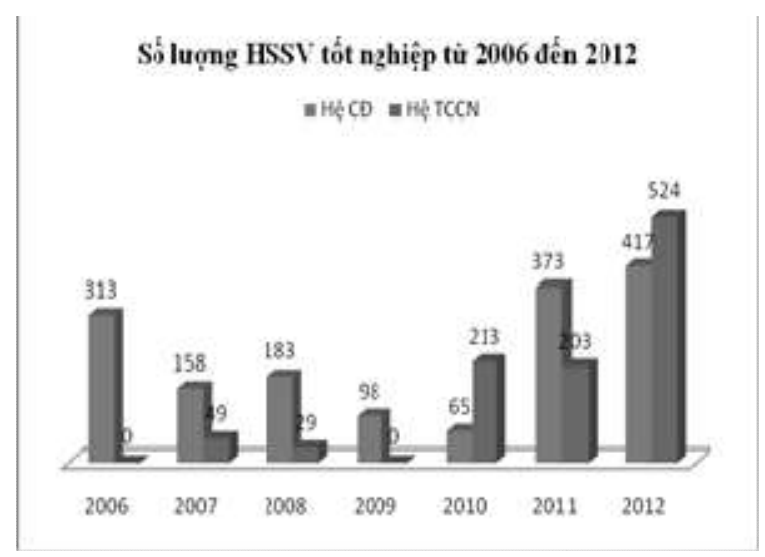

Biểu đồ 1

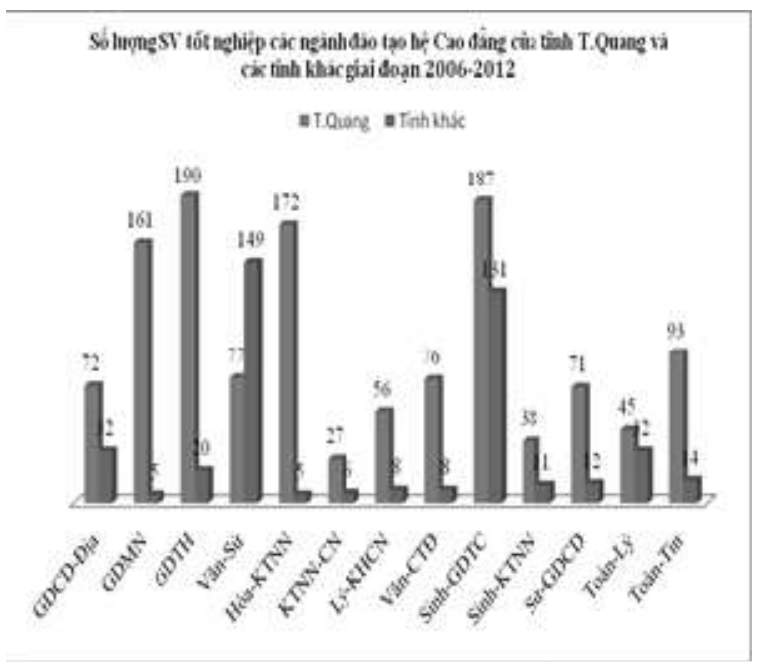

Biểu đồ 2

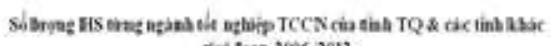
gaxisopa : 2006 : 2012

ate wiehing

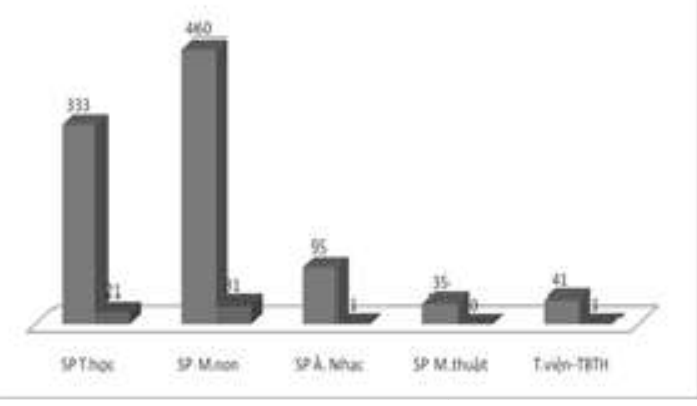

Biểu đồ 3

Như vậy, từ năm 2006 đến 2012 trong số 2.625 học sinh, sinh viên tốt nghiệp ra trường của Trường Đại học Tân Trào có 2.229 học sinh, sinh viên có hộ khẩu của tỉnh Tuyên Quang, phục vụ cho sự nghiệp phát triển kinh tế xã hội của tỉnh Tuyên Quang và số còn lại cung cấp cho khu vực Tây Bắc cũng như cả nước.

\subsection{Giai đog̣n 2013-2015}

Từ năm 2013, Trường Đại học Tân Trào được thành lập và mở các mã ngành đại học, vì vậy, giai đoạn này, Trường Đại học Tân Trào bắt đầu đào tạo nguồn nhân lực từ trình ại độ đhọc trở xuống với các loại hình chính quy, vừa làm vừa học, liên thông. Số lượng sinh viên do Trường Đại học Tân Trào đào tạo từ năm 2013 đến năm 2017 là 5.892 sinh viên, trong đó số sinh viên người Tuyên Quang là 5.096, chiếm 86,5\%, sinh viên người Hà Giang là 626 sinh viên, chiếm $10,6 \%$ còn lại là người của trên 30 tỉnh, thành phố khác. Giai đoạn 20132015, số sinh viên do Trường Đại học Tân Trào đào tạo là 4.597 trong đó sinh viên Tuyên Quang là 3.907 sinh viên, chiếm $85 \%$, sinh viên Hà Giang là 503 sinh viên, chiếm $10,9 \%$, còn lại là sinh viên của các tỉnh khác (Biểu đồ số 4).

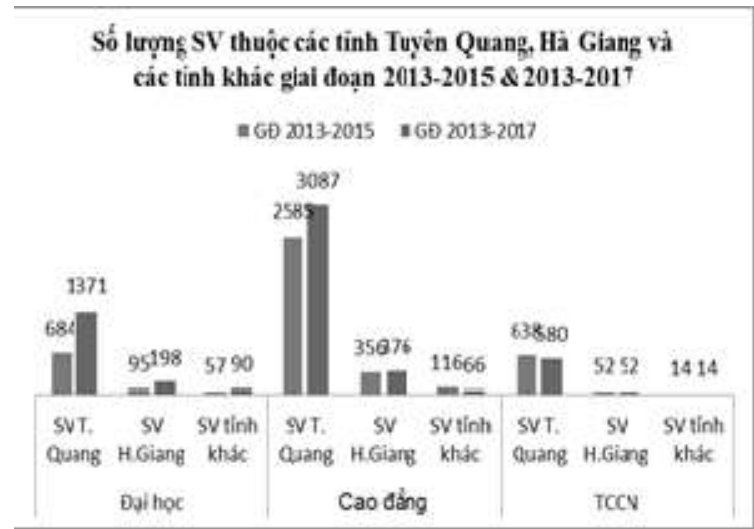

Biểu đồ 4 
3. Cơ cấu và trình độ đào tạo của cán bộ, công chức, viên chức tỉnh Tuyên Quang và Trường Đại học Tân Trào

3.1. Số luọng và trình độ của đội ngũ cán bộ, viên chức tỉnh Tuyên Quang

+ Về số luợng và cơ cấu (Biểu đồ 5):

(1) Thờ điểm 2010 (Báo cáo khảo sát 2012): Theo số liệu thống kê, đến hết năm 2010, tỉnh Tuyên Quang có 18.634 cán bộ $(\mathrm{CB})$, công chức $(\mathrm{CC})$, viên chức (VC). Trong đó, có $2.163 \mathrm{CB}, \mathrm{CC}$ làm việc trong các cơ quan hành chính nhà nước $(\mathrm{HCNN})$ cấp tỉnh, huyện; 828 cán bộ Khối đảng, đoàn thể, 14.443 viên chức làm việc trong các đơn vị sự nghiệp công lập (giáo dục: 11.495, y tế: 1.967 , văn hoá - thể dục thể thao: 384 , các tổ chức sự nghiệp khác: 578 ) và 1.603 $\mathrm{CB}$ làm việc trong các doanh nghiệp nhà nước.

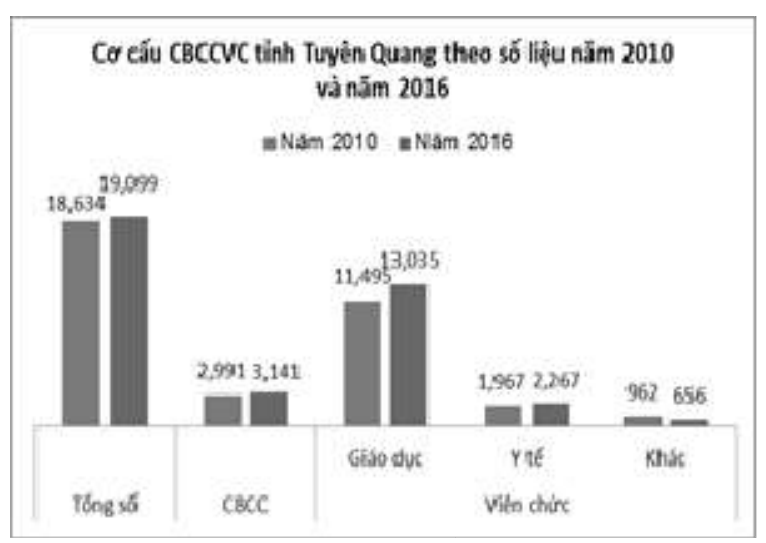

Biểu đồ 5

(2) Thời điểm 2015 (Báo cáo năm 2016): Tính toán theo báo cáo số 113/BC-UBND ngày 18/8/2016 của UBND tỉnh Tuyên Quang về "So kết 5 năm thục hiện kế hoạch phát triển nguồn nhân lực tỉnh Tuyên Quang giai đoạn 2011-2020", năm 2016 tổng số CB, $\mathrm{CC}, \mathrm{VC}$ toàn tỉnh là 19.099 người, trong đó số $\mathrm{CBCC}$ cấp tỉnh, huyện là 3.141 người, viên chức ngành giáo dục là 13.035 người, ngành y tế là 2.267 người, còn lại thuộc viên chức các ngành khác.

+ Về trình độ đào tạo (Biểu đồ số 6):

(1) Theo thống kê năm 2010, CB, VC thuộc cơ quan $\mathrm{HCNN}$ có 04 tiến sĩ, chiếm tỷ lệ $0,18 \%$; 54 thạc sĩ, chiếm tỷ lệ 2,5\%; 1.551 đại học, chiếm tỷ lệ 71,7\%; cán bộ khối đảng, đoàn thể có 42 thạc sĩ chiếm tỷ lệ 5,1\%, 606 đại học chiếm tỷ lệ $73 \%$; viên chức sự nghiệp có 03 tiến sĩ, 174 thạc sĩ, chiếm tỷ lệ 1,2\%; 4.966 đại học, chiếm tỷ lệ 34,4\%; viên chức thuộc các doanh nghiệp nhà nước có 15 thạc sĩ chiếm tỷ lệ $1,2 \%$, đại học 553 người chiếm 46\%. Như vậy đến 2010, có
2.257/2.991 cán bộ trong cơ quan HCNN, khối đảng, đoàn thể cấp tỉnh và huyện có trình độ đại học trở lên đạt 75,5\%,5.711/15.643 viên chức các đơn vị sự nghiệp, doanh nghiệp nhà nước có trình độ đại học trở lên, đạt $36,5 \%$.

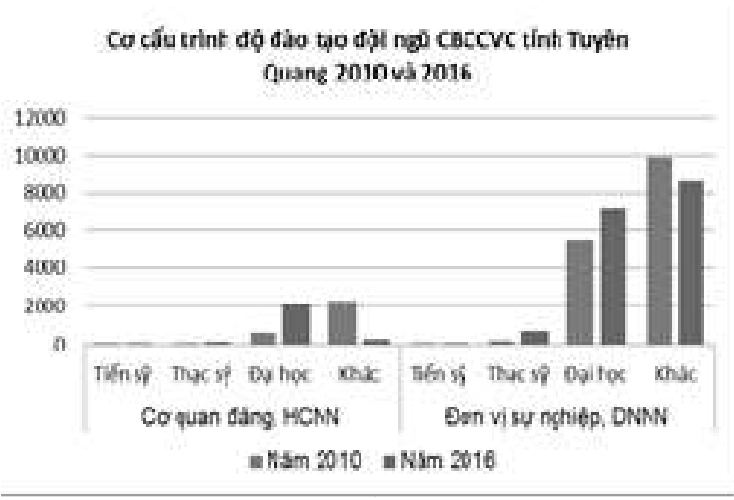

Biểu đồ 6

(2) Năm 2016, theo báo cáo số 113/BC-UBND ngày 18/8/2016 của UBND tỉnh Tuyên Quang về "So kết 5 năm thực hiện kế hoạch phát triển nguồn nhân lưc tỉnh Tuyên Quang giai đoạn 2011-2020", toàn tỉnh có $97,6 \%$ cán bộ, công chức tham mưu, nghiên cứu tổng hợp của cơ quan đảng, chính quyền, mặt trận tổ quốc và các đoàn thể cấp tỉnh, cấp huyện có trình độ chuyên môn từ đại học trở lên, tăng 9,6\% so với năm 2010, số cán bộ, công chức của các đơn vị cấp tỉnh, huyện có trình độ đại học trở lên là 3.065/3.141 CB, CC. Số viên chức của các đơn vị sự nghiệp nhà nước toàn tỉnh là 15.958 người, số người đạt chuẩn là 15.303 người.

\section{+ Đánh giá chung}

Từ số liệu khảo sát trên, có thể rút ra những nhận định cơ bản rằng trình độ chuyên môn của đội ngũ cán bộ, công chức, viên chức nhà nước của Tỉnh Tuyên Quang cơ bản đạt yêu cầu so với tiêu chuẩn ngạch, bậc $(\mathrm{CB}, \mathrm{CC}, \mathrm{VC}$ nhà nước có $97,6 \%$, viên chức các đơn vị sự nghiệp có $95,9 \%$ đạt chuẩn). Tuy nhiên, trình độ sau đại học còn chiếm tỷ lệ thấp (chỉ có trên $6,6 \%$ đối với các cơ quan khối đảng, đoàn thể và hành chính nhà nước, $4,8 \%$ đối với các đơn vị sự nghiệp và các doanh nghiệp nhà nước).

\subsection{Số lự̂ng và trình độ của đội ngũ cán bộ, giảng} viên Truò̀ng Đại học Tân Trào

Đội ngũ cán bộ giảng viên $(\mathrm{CBGV})$ của nhà trường trong giai đoạn 2006 đến 2009 giữ ổn định với 122 CBGV trên 144 biên chế, trong đó có 32 thạc sĩ, 02 tiến sĩ (năm 2009 còn 29 thạc sĩ, 01 tiến sĩ), đi học sau đại học 04, không có nghiên cứu sinh. Bắt đầu từ năm học 2010 đến 2012 , do quy mô tuyển sinh tăng mạnh, nhà trường 
đã mở rộng tuyển sinh ra cả nước nên số $\mathrm{CB}, \mathrm{GV}$ đã tăng nhanh, năm 2011 biên chế nhà trường là 165 , đến năm 2012 biên chế là 186 và đến nay là $308 \mathrm{CB}, \mathrm{GV}, \mathrm{NV}$ (cả hợp đồng lao động). Cùng với biên chế $\mathrm{CB}, \mathrm{GV}$ tăng, do cơ chế khuyến khích của nhà trường nên số người đi học sau đại học và nghiên cứu sinh tăng rất nhanh, tính đến hết 2012, Trường Cao đẳng Tuyên Quang có 82 thạc sĩ (tăng 3 lần so với năm 2009), 03 tiến sĩ, 57 người đi học sau đại học (tăng gần 15 lần so với năm 2009) và 24 người đi làm nghiên cứu sinh trong và ngoài nước (tăng trên 20 lần), đó là một cơ sở quan trọng để ngày 14 tháng 8 năm 2013 Thủ tướng Chính phủ đã ký Quyết định số 1404/QĐ-TTg thành lập Trường Đại học Tân Trào trên cơ sở nâng cấp trường Cao đẳng Tuyên Quang. Đến năm 2015 số tiến sỹ của Đại học Tân Trào là 17 người (chiếm gần $10 \%$ số giảng viên trực tiếp giảng dạy, số thạc sĩ là 165 người (chiếm gần $82 \%$ số giảng viên trực tiếp giảng dạy), đến nay sau 5 năm thành lập đại học, số tiến sĩ của nhà trường là 29 người (tăng gần 10 lần so với năm 2012, chiếm gần $15 \%$ số giảng viên trực tiếp giảng dạy), số thạc sĩ là 179 người (tăng hơn 2 lần so với năm 2012 và chiếm trên $85 \%$ số giảng viên trực tiếp giảng dạy). Qua các số liệu đã minh chứng cho thấy sự phát triển mạnh mẽ của Trường Đại học Tân Trào về nguồn nhân lực phục vụ cho các hoạt động đào tạo, nghiên cứu khoa học và hợp tác quốc tế giai đoạn 2006-2015 (Biểu đồ số 7).

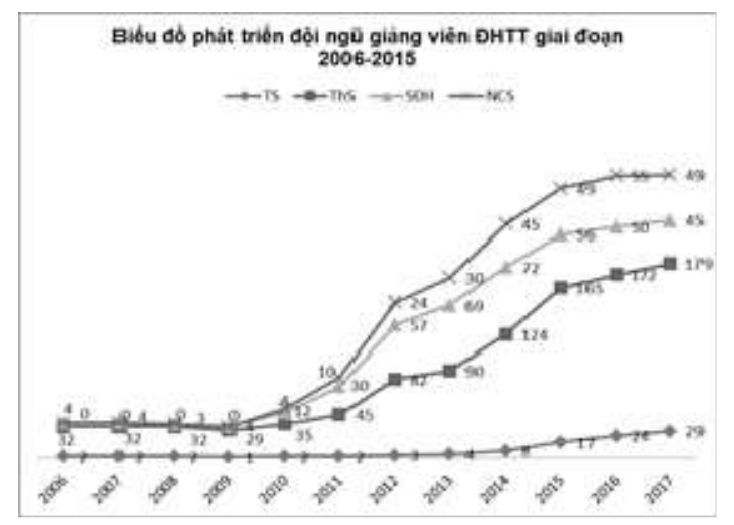

Biểu đồ 7

4. Đánh giá hiệu quả đào tạo của Trường Đại học Tân Trào giai đoạn 2006 - 2015 trong sự phát triển kinh tế xã hội của tỉnh Tuyên Quang và khu vực Tây Bắc

Việc đánh giá hiệu quả đào tạo của Trường Đại học Tân Trào đối với sự phát triển kinh tế - xã hội của tỉnh Tuyên Quang và khu vực là hết sức cần thiết và từ đó sẽ có các giải pháp phát triển Trường Đại học Tân Trào trong giai đoạn sau 2020. Trong khuôn khổ và phạm vi nghiên cứu này, đơn giản chỉ so sánh số lượng sinh viên của Trường Đại học Tân Trào đào tạo với số lượng cán bộ viên chức ngành giáo dục, đồng thời thống kê số lượng sinh viên của các tỉnh khác do Trường Đại học Tân Trào đào tạo để đánh giá sự đóng góp của Trường Đại học Tân Trào vào sự phát triển nguồn nhân lực và rộng ra là đóng góp vào sự phát triển kinh tế-xã hội. Chất lượng nguồn nhân lực và đội ngũ do nhà trường đào tạo sẽ được đánh giá trong một nghiên cứu khác.

Theo Biểu đồ 5, với tổng số $11.495 \mathrm{CB}, \mathrm{VC}$ ngành giáo dục theo thống kê năm 2012, số $\mathrm{CB}$, VC thuộc 4 trường cao đẳng, trung cấp chuyên nghiệp là 386 người chiếm hơn $3 \%$, số $\mathrm{VC}$ thuộc các trường trung học phổ thông, các trung tâm GDTX của tỉnh, văn phòng Sở Giáo dục và Đào tạo, các phòng Giáo dục và Đào tạo huyện, thành phố... tổng cộng 2.675 người chiếm xấp xỉ $14 \%$ và số cán bộ, viên chức thuộc các trường trung học cơ sở, tiểu học, mầm non trong toàn tỉnh có trình độ cao đẳng, trung cấp khoảng gần 9.000 người, chiếm $65 \%$ tổng số viên chức ngành Giáo dục và Đào tạo (số cán bộ giáo viên này cũng phần lớn là do Trường Đại học Tân Trào đào tạo trong giai đoạn từ năm 1999-2006). Như vậy, số học sinh, sinh viên do Nhà trường đào tạo để sử dụng trong ngành giáo dục trong giai đoạn 20062012 là 2.625 học sinh, sinh viên tốt nghiệp với nhiều ngành khác nhau, trong đó có 2.229 học sinh, sinh viên người Tuyên Quang chiếm gần $18 \%$ số cán bộ viên chức của ngành tại thời điểm khảo sát (Biểu đồ số 8 ).

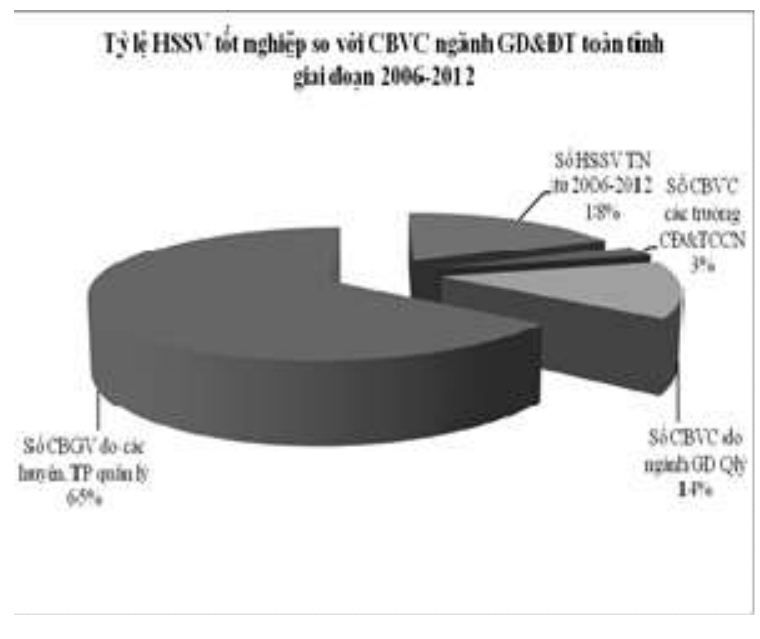

Biểu đồ 8

Giai đoạn 2013-2015 số sinh viên của nhà trường đã tốt nghiệp là 3.711 (chưa có SV tốt nghiệp hệ đại học) chiếm tỷ lệ gần $25 \%$ số cán bộ giảng viên ngành giáo dục có trình độ cao đẳng, trung cấp tính đến năm 2015. Nếu so sánh tỷ lệ trong số lượng cán bộ, công chức, viên chức toàn tỉnh Tuyên Quang với tổng số 
trên 18.945 người thì ngành giáo dục chiếm tỷ lệ lớn nhất hơn $62 \%$, tiếp đến là khối hành chính nhà nước chiếm khoảng $11 \%$, y tế chiếm $10 \%$, các ngành khác chiếm khoảng 1\%. Trong khi đó, số lượng học sinh, sinh viên tốt nghiệp tại Trường Đại học Tân Trào giai đoạn 2006-2015 chiếm tới khoảng 16\% tổng số cán bộ viên chức toàn tỉnh Tuyên Quang và có đóng góp cho các tỉnh lân cận trong khu vực (Biểu đồ số 9).

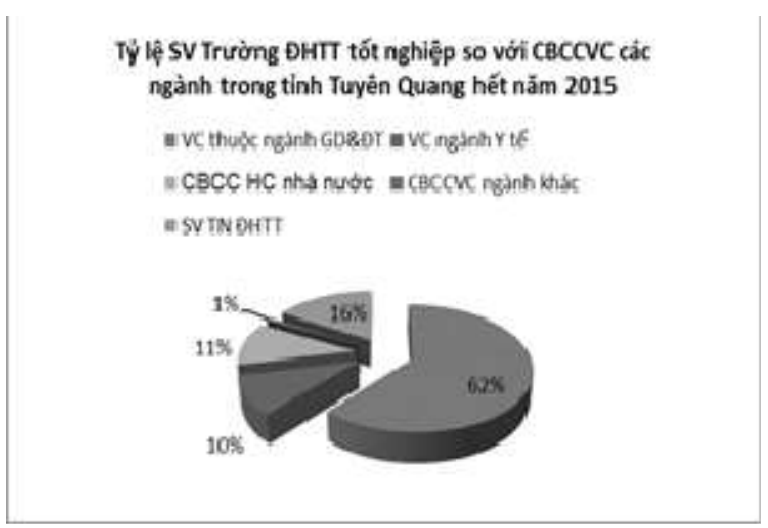

Biểu đồ 9

Như vậy, với những phân tích trên, rõ ràng nguồn nhân lực do Trường Đại học Tân Trào đào tạo cả hai giai đoạn 2006-2012 và 2013-2015 đã có tác động hiệu quả và có vai trò to lớn góp phần phục vụ sự phát triển kinh tế xã hội của tỉnh Tuyên Quang và một số tỉnh khu vực Tây Bắc và cả nước.

\section{Kết luận}

Trường Đại học Tân Trào, Tuyên Quang trong những năm qua đã đào tạo được hàng vạn giáo viên, cán bộ quản lý giáo dục các cấp và cán bộ các ngành khác phục vụ cho sự nghiệp phát triển kinh tế - xã hội của tỉnh Tuyên Quang, khu vực Tây Bắc và cả nước. Hàng năm, sinh viên tốt nghiệp ra trường được tiếp nhận làm việc tại các cơ sở giáo dục với tỷ lệ cao, cung cấp thêm nguồn nhân lực cho ngành giáo dục và các ngành khác cả về số lượng và chất lượng. Hầu hết sinh viên được đào tạo tại trường, đến nay đã trưởng thành về mọi mặt, có trình độ chuyên môn vững vàng, có năng lực trong công tác quản lý, nhiều người đã trở thành cán bộ quản lý tại các cơ sở giáo dục và các cơ sở khác. So sánh số lượng sinh viên đã được nhà trường đào tạo giai đoạn 2006-2015 và số lượng cán bộ, công chức, viên chức của tỉnh Tuyên Quang, số lượng sinh viên tốt nghiệp công tác tại các tỉnh khác trong khu vực đã khẳng định vị trí và vai trò to lớn cũng như hiệu quả đào tạo của nhà trường trong sự phát triển kinh tế xã hội của tỉnh Tuyên Quang, khu vực Tây Bắc và cả nước.

\section{TÀI LIỆU THAM KHẢO}

1. Báo cáo Tổng kết Đề tài khoa học cấp tỉnh "Khảo sát và đánh giá chất lượng nguồn nhân lực do Truờng Cao đẳng Tuyên Quang đào tạo giai đoạn 20062012”, Sở KH\&CN Tuyên Quang, tháng 5/2015;

2. Báo cáo số 198/BC-UBND ngày 29/7/2016 của UBND tỉnh Lào Cai về "So kết 5 năm thưcc hiện kế hoạch phát triển nguồn nhân lục tỉnh Lào Cai giai đoạn 2011-2020";

3. Báo cáo số 113/BC-UBND ngày 18/8/2016 của UBND tỉnh Tuyên Quang về "So kết 5 năm thục hiện kế hoạch phát triển nguồn nhân lực tỉnh Tuyên Quang giai đoạn 2011-2020";

4. Kế hoạch số 06-KH/TU ngày 13/6/2011 của Tỉnh uỷ Tuyên Quang về "Kế hoạch đào tạo, bồi duõng cán bộ công chức thực hiện mục tiêu Nghị quyết Đại hội Đảng bộ tỉnh Tuyên Quang lần thư XV, nhiệm kỳ 2010-2015”;

5. Kế hoạch số 2471/UBND-VX ngày 16/11/2011 của UBND tỉnh Tuyên Quang về "Đào tạo bồi duõng cán bộ công chức, viên chức năm 2012”;

6. Nghị quyết số $02-N Q / T U$ ngày 13/2/2011 của Ban Chấp hành Đảng bộ tỉnh (khoá XV) về phát triển và nâng cao chất luợng nguồn nhân lực tỉnh Tuyên Quang giai đoạn 2011 - 2015, định huớng đến năm 2020;

7. Nguồn số liệu thống kê số lượng học sinh sinh viên của phòng Quản lý sinh viên Trường Đại học Tân Trào;

8. Quyết định số 2022/QĐ-UBND ngày 22/9/2011 của Chủ tịch Ủy ban nhân dân tỉnh Hà Giang về phê duyệt Quy hoạch phát triển nguồn nhân lực tỉnh Hà Giang giai đoạn 2011 -2020;

9. Quyết định số 121/NQ-UBND ngày 12/5/2012 của Chủ tịch Ủy ban nhân dân tỉnh Tuyên Quang về phê duyệt Quy hoạch phát triển nguồn nhân lực tỉnh Tuyên Quang giai doạn 2011 -2020;

10. Quyết định số 22/QĐ-UBND ngày 24/7/2016 của Chủ tịch Ủy ban nhân dân tỉnh Yên Bái về phê duyệtQuy hoạch phát triển nguồn nhân lục tỉnh Yên Bái giai đoạn 2016 -2020. 


\section{Tan Trao University with the role of training human resources for socio- economic development of Tuyen Quang province and some other provinces in the Northwest region of Viet Nam in the 2006-2015 period}

Nguyen My Nga; Pham Thi Thu Huyen; Nguyen My Viet

\section{Article info}

Recieved:

26/01/2018

Accepted:

$10 / 3 / 2018$

\section{Keywords:}

Students; human;

officer; civil servants;

Northwest.

\section{Abstract}

The Tan Trao University has established at 14th August, 2013 by decided of Prime Minister of Viet Nam goverment, is a public university with the task are training, scientific research and international cooperation of the Tuyen Quang province and region of the Northwest mountains. Over the years, Tan Trao University awarded annually and provides training for Tuyen Quang province and other provinces in the country serving thousands of staff for education and training sector, manager and other sectors. Compare to the number of students who have been trained in the Tan Trao University 2006-2015 period and the number of officials, civil servants, and administrator of Tuyen Quang, and at the same time statistic the number of students from neighboring provinces trained by Tan Trao University, has affirmed location and a great role in the task of training human resources sevices for socio-economic development of Tuyen Quang province in particular and the Northwest region and the country in general of the University of Tan Trao. 